\title{
LAS NUEVAS FORMAS DE REGULACIÓN NEOLIBERAL
}

\section{JOSÉ ANTONIO ESTEVEZ ARAUJO}

Universidad de Barcelona - España

jaesaraujo@telefonica.net

Artigo submetido em espanhol 
La globalización neoliberal no sólo ha supuesto desregulación y privatización. No se ha limitado a disminuir el poder del Estado y aumentar el del mercado. Sin embargo, quienes lo critican a veces parecen creerlo así. Con ocasión de la crisis financiera, se atribuyó su causa a la desregulación y su remedio se vio en una nueva regulación del sistema financiero. Por otra parte, los estudiantes españoles contrarios al proceso de Bolonia denuncian el riesgo de privatización de la universidad. No obstante, las contraposiciones regulación/desregulación y público/privado, son insuficientes para entender las transformaciones que han tenido lugar en el ámbito jurídico-político como consecuencia de la globalización neoliberal, y pueden hacer ineficaces las críticas que se hagan. Hay que tener claro que el neoliberalismo no sólo ha consistido en privatización y desregulación, sino que ha implantado nuevas maneras de regular y una concepción distinta de la relación entre lo público y lo privado.

\section{LA DESREGULACIÓN}

La desregulación puede entenderse como un dar marcha atrás respecto de la regulación que el Estado había llevado a cabo durante el siglo XX. Desde el punto de vista jurídico esa regulación restringía la libertad de contratación y de actuación de los sujetos privados. Suponía que las normas estatales imponían un mayor número de obligaciones a los sujetos con independencia de su voluntad. Desde el punto de vista económico, la regulación significó una mayor intervención del Estado en el funcionamiento del mercado.

La desregulación no sólo significa la abolición de esas regulaciones. La desregulación también se constitucionaliza, es decir, se prohíbe al Estado restablecer las antiguas regulaciones. En el ámbito europeo esta "constitucionalización" se realiza fundamentalmente por medio de la normativa comunitaria. Por otro lado el proceso de desregulación no ha terminado. Así por ejemplo la nueva directiva europea de servicios (la anteriormente llamada "Directiva Bolkestein") desregula ese sector de la economía, prohibiendo a los poderes públicos que reglamenten su actividad en muchos aspectos.

Pero con el neoliberalismo no sólo se desregula, sino que, además, se regula de otra manera. En lo que sigue, se va a hablar de esas nuevas formas de regulación.

\section{UN NUEVO DERECHO PRIVADO: LA LEX MERCATORIA}

La globalización económica ha dado lugar a un incremento exponencial de las transacciones transfronterizas. Ese incremento ha sido consecuencia de la liberalización de la circulación de mercancías y capitales a través de las fronteras. Sin embargo, no ha habido una homogeneización de los derechos estatales en materia de contratación ni se ha producido un derecho interestatal de los contratos. El derecho de contratos de los diversos estados sigue respondiendo a principios muy diferentes y no se han adoptado normas de derecho internacional que regulen los contratos transnacionales.

Por otro lado, las normas de derecho internacional privado que determinan la normativa aplicable y el juez competente son insuficientes para atender las nuevas necesidades jurídicas del mercado global. El grado de incertidumbre es muy grande, se plantean problemas de interpretación de las propias normas de DIP y las consecuencias de verse sometido a uno u otro ordenamiento pueden ser muy diferentes (aunque también es verdad que las firmas de abogados ofrecen servicios de Shopping jurídico, o búsqueda del derecho más favorable para que sus clientes sometan a él los contratos de los que son parte). ${ }^{1}$

Hendu 1 (1): julho, 2010 
En cualquier caso, la regulación del creciente número de negocios internacionales consecuencia de la globalización no se ha realizado prioritariamente mediante normas jurídicas producidas por los estados. Lo que ha ocurrido es que ha surgido un nuevo derecho producido y aplicado por instancias privadas: la llamada "nueva Lex Mercatoria".

En el marco de la Lex Mercatoria, el principal productor de normas jurídicas es la Law Firm, la firma de abogados al estilo anglosajón, que se gestiona con criterios empresariales y que es ella misma una empresa multinacional. El principal servicio que ofrecen estas Law firms a otras empresas multinacionales es la elaboración de contratos. Se trata de contratos "sin ley", que responden al modelo contractual del common law. Es decir, son contratos que no presuponen un sistema jurídico estatal que los dote de validez y, sobre todo, que supla sus lagunas. Se plasman, por ello, documentos muy extensos (en comparación con los europeo-continentales) con infinidad de cláusulas que pretenden prever todas las eventualidades y resolver todas las dudas posibles (se cita el ejemplo de uno de estos contratos que entre sus cláusulas contenía una que decía "en este contrato se entenderá por 'día' un periodo de tiempo de 24 horas"). Los abogados que elaboran y negocian estos contratos poseen un tipo de saber jurídico distinto del que se adquiere en las facultades de derecho europeocontinentales y en los despachos de abogados franceses, alemanes o españoles, tradicionalmente más centrados en la litigación.

El trabajo normativo de las Law Firms no sólo cristaliza en la elaboración de contratos individualizados, sino también de contratos tipo. De hecho, las nuevas clases de contratos mercantiles que han aparecido en los últimos tiempos (leasing, franquicia...) no han sido creados por las legislaciones estatales o por acuerdos internacionales, sino que son fruto de la actividad de las Law Firms $^{l}$. Y La inversión de la relación entre contrato y "ley" se pone de manifiesto en el hecho de que las normas generales aplicables a los contratos internacionales son el resultado de la generalización y abstracción a partir de las cláusulas de los contratos particulares. En este sentido se habla de los "usos de los negocios" como fuente de la lex mercatoria y en este sentido también, los textos jurídicos elaborados por UNIDROIT (por ejemplo el relativo a la franquicia) no son sino recopilaciones hechas a partir del contenido de los contratos elaborados por las Law Firms.

Las Law Firms no sólo elaboran contratos y contribuyen a "crear" usos, sino que también producen doctrina "científica", bien directamente, bien colonizando determinadas cátedras de las universidades. También, en ocasiones, se paga a profesores universitarios para la elaboración de dictámenes con el objetivo de que sean publicados como "doctrina" en una revista académica.

La lex mercatoria puede ser considerada una nueva forma de "regulación". En el ámbito de las transacciones transfronterizas, la desregulación no ha conducido de nuevo a lo que los sociólogos del derecho denominan paradigma jurídico "formal". Este consiste en la existencia de un derecho estatal que establece las condiciones de validez de los contratos y regula supletoriamente las obligaciones de los contratantes. Y aquí, lo que ha tenido lugar es el surgimiento de un nuevo derecho privado en el que la firma de abogados sustituye al estado, el contrato a la ley y el árbitro al juez.

La única contribución relevante del derecho de origen estatal a la satisfacción de las exigencias jurídicas del mercado global ha sido el reforzamiento de la propiedad intelectual. Es decir, no ha surgido una regulación de derecho internacional de los contratos o de la resolución de conflictos en los negocios transnacionales. Pero sí se han aprobado normas de derecho internacional que aseguran la protección de la propiedad intelectual: los llamados acuerdos ADPIC (acuerdos relativos a la propiedad intelectual relacionados con el comercio). 


\section{$\underline{\text { La Autorregulación }}$}

La llamada "autorregulación" es una forma de regulación que hubiera resultado insólita hasta los años setenta del siglo pasado: se trata de que los propios sujetos que deben ser regulados dicten las normas a las que tiene que ajustarse su conducta y controlen su cumplimiento.

La autorregulación se basa en una serie de mitos fundacionales. Se trata de unos presupuestos asumidos dogmáticamente que pretenden fundamentar esta forma de "regular".

El primero de estos mitos es el de la crisis del estado del bienestar que nadie parece discutir. Pero ¿de qué crisis se está hablando? El estado del bienestar no sufrió un colapso interno como parece dar a entender este mito. En realidad, el estado del bienestar fue desmantelado desde fuera.

El segundo de estos mitos es el de la crisis regulatoria del derecho, es decir que la capacidad que el derecho tiene de regular se enfrenta a unos límites intrínsecos. Y estos límites se habrían traspasado en la época del estado del bienestar. Esta tesis la defendieron sobre todo los juristas luhmanianos como Teubner, pero también la sustentó Habermas en los años ochenta cuando sostuvo que se había producido una "juridificación" del mundo de la vida?

Íntimamente relacionado con este mito está el dogma del carácter autopoiético de los subsistemas sociales. Este dogma sostiene que cada subsistema social (la economía, la política, el derecho o la ciencia) tiene sus propios mecanismos de reproducción, autónomos respecto de los de los demás. Eso significa que los "estímulos" que nazcan de un subsistema sólo pueden producir efectos en los demás si son metabolizables por éstos y sólo en la medida en que lo sean. Así el derecho sólo puede percibir y reaccionar frente a los "hechos" en la medida en que pueda convertirlos en fenómenos jurídicos (p. ej. en "hechos probados"). Esto significa que un sistema no puede influir directamente en otro. Más en particular, que el sistema político no puede pretender regular el funcionamiento del sistema económico sin generar consecuencias contraproducentes. Los diferentes subsistemas tienen que autorregularse.

Todos estos mitos pueden encontrarse expuestos en una obra de referencia en esta materia: el libro editado por Teubner en los años ochenta sobre la crisis del derecho en el estado del bienestar ${ }^{4}$. Y se puede comprobar que dichos mitos son recogidos acríticamente por los juristas que se ocupan del tema de la autorregulación ${ }^{5}$.

La autorregulación tiene dos manifestaciones principales. Una de ellas consiste en la elaboración de normas por parte de los mismos colectivos que deben sujetarse a ellas. El ejemplo más importante lo constituyen las normas técnicas elaboradas por asociaciones de fabricantes (sólo hay que pensar en la importancia que tiene el establecimiento de unos estándares comunes a los que deben ajustarse los aparatos digitales para poderse interconectar, por ejemplo, mediante los puertos USB).

La otra manifestación de la autorregulación que tiene creciente importancia son los códigos de conducta que regulan la llamada "responsabilidad social" de las empresas. Se trata de unas normas elaboradas por las empresas mismas (en materias medioambientales o de derechos humanos) y que éstas se comprometen a cumplir, pero que no resultan jurídicamente exigibles ante ninguna instancia administrativa o judicial. Existen también formas de autorregulación que consisten en el autocontrol que ejercen un conjunto de empresas en relación a un código de conducta colectivo (por ejemplo, en el caso español, el control de la publicidad).

Hay ya bastantes estudios que ponen de manifiesto que los códigos de conducta de las empresas

Hendu 1 (1): julho, 2010 
suelen ser absolutamente ineficaces por sí mismos. Se trata más bien de operaciones publicitarias para vender una determinada imagen de marca. Pero cuando se indaga en qué condiciones trabajan los empleados de los subcontratistas que elaboran los productos de la marca, se ponen de manifiesto continuas violaciones de los compromisos adquiridos en materia de respeto de los derechos, laborales, sindicales y, más en general, humanos ${ }^{6}$.

\section{LA TRANSFORMACIÓN DE LA ADMINISTRACIÓN PÚBLICA}

La globalización neoliberal ha traído consigo privatizaciones. Y en gran cantidad. Pero también ha supuesto la implantación de nuevas formas de funcionamiento de los entes públicos. Esta transformación ha consistido en la sustitución de la racionalidad burocrática por formas de gestión similares a las de la empresa privada.

La empresa se ha presentado en estos últimos decenios como el modelo de organización a imitar en todos los ámbitos. Uno de los autores del informe de la trilateral sobre la crisis de las democracias, el francés Crozier, llega a considerar a la empresa como la institución civilizatoria por excelencia? Dentro de las empresas, el modelo japonés es el que suele servir de punto de referencia en el mundo de la globalización neoliberal.

En este marco de cultura "empresarial", la eficacia y la capacidad de innovación se han convertido en dos de los valores más importantes a los que debe ajustarse el funcionamiento de todas las instituciones. La capacidad de innovar se traduce en la creación de nuevos productos, en la puesta a punto de nuevos métodos o de nuevas formas de organización. La empresa japonesa se ha mostrado más apta para innovar, porque sabe aprovechar mejor la creatividad de sus empleados. Tiene una forma de funcionamiento que le permite incorporar de modo continuo las mejoras que introducen los trabajadores en los procesos productivos. Se contrapone, así, a la organización rígida y burocrática propia del taylorismo, aunque eso no signifique necesariamente que las innovaciones redunden en beneficio de los empleados. Pueden, por el contrario, significar un mayor nivel de exigencia en relación con los ritmos productivos.

El control de calidad es otro aspecto en el que las empresas japonesas se adelantaron a las norteamericanas en el mundo de la globalización. Aunque fueron los norteamericanos los inventores de los métodos para evaluar la calidad de la producción han sido los japoneses los que han generado los últimos desarrollos en este campo.

El New Public Management o Nueva Gestión Pública es el nombre con el que se suele designar al modelo que traspasa estos métodos de gestión empresarial al ámbito de la Administración pública ${ }^{8}$. La característica fundamental de la nueva gestión pública es que la definición de objetivos y la auditoría sustituyen a la racionalidad burocrática basada en imperativos condicionales y control jerárquico. Es decir, desplazan una forma de funcionamiento que se basa en normas que establecen cómo debe actuar el funcionario en un supuesto determinado y en un control jerárquico y judicial del ajuste de su actuación al reglamento.

El funcionamiento de los órganos administrativos de gestión o de las entidades prestadoras de servicios públicos se regula, pues, mediante el establecimiento de los objetivos a alcanzar y de los requisitos de calidad que se deben cumplir. Esto supone la implantación de una racionalidad teleológica acompañada del establecimiento de estándares objetivos de calidad ${ }^{9}$.

El control de la actividad de los órganos administrativos se realiza mediante auditorías. Es decir, se generaliza el mecanismo consistente en la realización de evaluaciones externas que utilizan estándares 
objetivos para evaluar los resultados de la actividad administrativa. En el término "auditoría" se incluyen los cuerpos de inspección, los órganos de evaluación, las agencias de calidad, etc. que tienen como objetivo valorar el desempeño (performance) de la entidad o de la persona auditada. El NPM ha dado lugar a lo que un autor ha denominado "la explosión de las auditorías"10. Esta explosión ha consistido en que la auditoría ha pasado de tener un carácter secundario (en el ámbito de la Administración) y centrado en la contabilidad a extenderse a todos los campos y dimensiones de actividad de la administración: hospitales, prisiones, centros de enseñanza, grupos de investigación...

La definición de la actividad a realizar en base a los objetivos a alcanzar y a los estándares que deben cumplir, facilita que una actividad realizada por un ente público se transfiera a un ente privado. O sea que puede ser un expediente previo a la privatización de un servicio o una función pública. Por otro lado, se puede recurrir a entidades privadas para que lleven a cabo auditorías sobre las entidades públicas. Así, por ejemplo, para determinar si un organismo público cumple los estándares establecidos en la ISO 9000 acerca de la buena organización. También, las agencias de rating pueden auditar el grado de fiabilidad de la deuda pública emitida por los estados. Esto supone una clara subversión de la relación tradicional entre entidades públicas y privadas. No sólo se limita la capacidad de control público sobre la actividad privada por medio de la desregulación, sino que las entidades privadas pasan a controlar la actuación de las entidades públicas (e incluso a dictar las normas por las que se deben regir -como la propia ISO 9000).

En un mundo en el que se fuerza a las entidades públicas a actuar como si fueran empresas privadas y en el que las entidades privadas tienen el poder de evaluar y controlar la actividad de los entes públicos, los peligros para la Universidad, como para cualquier otro ente público, no provienen, pues, sólo de la amenaza de una privatización. El Rector de la Universidad de Barcelona puede afirmar en la televisión que no hay peligro de privatización de la universidad y no mentir. ¿Quién iba a querer comprar la UB tal como está ahora? El peligro proviene de que se gestione con criterios propios de una empresa (eficacia, rentabilidad, consecución de objetivos fijados desde fuera, patrones de calidad establecidos en función de las necesidades del "mercado" -las famosas "competencias"...) o que quede sometida al control de las empresas privadas.

Además de lo señalado en el párrafo anterior, la explosión de las auditorías genera una serie de perversiones ${ }^{11}$.

En primer lugar, los sujetos o entidades que dependen de una auditoría orientan su actividad a la producción de resultados con características que sean valoradas según los estándares de calidad que aplicarán las entidades auditoras. Eso puede producir resultados contraproducentes. P. ej. para un hospital puede ser "mejor" curar tres enfermos agudos que tres enfermos crónicos (porque éstos consumen más recursos), o para un profesor que tiene que ser "acreditado" puede ser mejor publicar un artículo en una revista indexada que una monografía.

Por ceñirnos a este último caso, el problema no es que los artículos publicados en revistas indexadas sean mejores trabajos que las monografías, sino que el auditor tiene unos criterios cuantitativos para valorar los artículos publicados en revistas (los índices que atribuyen una puntuación determinada a cada revista que logra ser incluida en los mismos) y no dispone de unos criterios tan claramente objetivados para las monografías. Por otro lado, ni los "índices de impacto" (número de veces que es citado un artículo o una revista), ni la peer review (examen anónimo de los artículos por consultores externos a las revistas), ni la inclusión en las listas de revistas indexadas aseguran la calidad de los artículos (como lo puso de manifiesto los dos artículos de unos investigadores coreanos sobre células madre, basados en una investigación fraudulenta, que lograron ser publicado en la revista

Hendu 1 (1): julho, 2010 
Science ${ }^{12}$ ). La posibilidad de publicar, las veces que alguien es citado, la inclusión en índices puede perfectamente ser expresión del poder gremial y clientelar de determinadas escuelas. El problema no estriba tanto en que se utilicen índices y criterios cuantitativos, el problema es que se usen con carácter exclusivo y de forma rígida, siendo esa otra de las perversiones de la explosión de las auditorías.

Por otro lado, pueden darse casos (y se han dado algunos sonados) de connivencia entre auditores y auditados. Los auditores pueden fácilmente pasar de ser controladores a convertirse en asesores sobre cómo pasar mejor la auditoría (en particular, si los auditados son "clientes" de los auditores o si las empresas auditoras prestan, además, otros servicios). Es lo que ha ocurrido con las agencias de rating en la última crisis financiera. Estas entidades pasaron de auditar el riesgo de los bonos emitidos por determinados bancos a aconsejarles cómo "estructurarlos" para que obtuvieran la máxima calificación.

Y last but not least está el problema de quién controla a los auditores. En determinadas ocasiones los auditores se autorregulan en el sentido en que más arriba se ha usado esta expresión. Es decir, tienen la obligación de someterse a un código de conducta, que a veces ha sido elaborado por ellos mismos, y cuyo cumplimiento también controlan ellos sin que ningún órgano público tenga la capacidad de supervisarlo. La actuación de las agencias de rating en la última crisis financiera o la de Arthur Andersen en el caso Enron ponen de manifiesto la poca fiabilidad de esta forma de regulación cuando hay muchas expectativas de beneficio de por medio.

\section{Y, POR FIN, LA GOBERNANZA}

Frecuentemente se utiliza el término "gobernanza" para referirse a todas estas nuevas formas de regulación y de gestión administrativa que han surgido en el marco de la globalización neoliberal. Aquí hablaremos de la "constelación de la gobernanza" para indicar que usamos el término en ese sentido. La constelación de la gobernanza se instaura en un espacio en el que el poder de los estados ha disminuido a favor de los mercados y los agentes económicos y comprende de forma articulada la desregulación, la lex mercatoria, la autorregulación, la nueva gestión pública y una nueva forma de tomar e implementar decisiones políticas que llamaremos "gobernanza" en sentido estricto. Las diversas formas de regular y gestionar no eliminan las anteriores a medida que surgen, ni suponen que se dé por terminada la desregulación, sino que se van agregando y articulando para configurar una constelación.

En ocasiones la expresión "gobernanza" incluye también las formas tradicionales de regulación jurídica (que obviamente, subsisten, redimensionadas, junto a las nuevas). Es el caso del Libro Blanco sobre la Gobernanza publicado por la Comisión Europea en 2001 donde se dice: "El concepto de 'gobernanza' designa las normas, procesos y comportamientos que influyen en el ejercicio de los poderes a nivel europeo (...)". Añadiendo que "La vía legislativa constituye a menudo tan sólo una parte de una solución más amplia, que combina normas formales con otros instrumentos no vinculantes, como recomendaciones, directrices o incluso instrumentos de autorregulación dentro de un marco acordado conjuntamente" y que "La corregulación combina medidas legislativas o reglamentarias vinculantes y medidas adoptadas por los agentes más interesados sobre la base de su experiencia práctica."

Sin embargo, si utilizamos el término "gobernanza" en sentido estricto, debemos distinguir entre la retórica de la gobernanza y la forma real de tomar decisiones e implantarlas.

La retórica de la gobernanza insiste especialmente en la participación de la "sociedad civil" en los 
procesos de toma de decisiones. Se presenta ante todo como una forma de decidir que consiste en una discusión racional entre los diferentes grupos de afectados y entre éstos y las autoridades. Un ejemplo de esto lo encontramos también en el libro blanco de la UE: "El modelo lineal consistente en decidir las políticas desde arriba debe ser sustituido por un círculo virtuoso basado en la interacción, en las redes existentes y en una participación a todos los niveles, desde la definición de las políticas hasta su aplicación".

La expresión "círculo virtuoso" tiene que ver con otro de los elementos de la retórica de la gobernanza que un autor ha formulado contraponiendo la solución de problemas (propia de la gobernanza) a la reclamación de derechos ${ }^{13}$. Se presenta entonces la gobernanza como un mecanismo que hace posible que la diferencia de planteamientos y posturas no conduzca a la contraposición o al bloqueo, sino que se convierta en un elemento de enriquecimiento del debate.

La retórica de la gobernanza también la presenta como un mecanismo que hace posible el aparente oxímoron de la coordinación descentralizada. Es decir, que reúne las ventajas de la coherencia y la coordinación propias de la burocracia, con la apertura y flexibilidad propias de las redes sociales. Así, Roberto Mangabeira Unger (profesor de la Universidad de Harvard, miembro destacado del movimiento de los Critical Legal Studies y actual Ministro de Planeación Estratégica el gobierno de Lula en Brasil), representante de la corriente que puede calificarse como más progresista de la gobernanza (el "experimentalismo democrático") señala en un libro programático titulado "Democracia realizada" que la "coordinación descentralizada" es uno de los objetivos centrales de su propuesta ${ }^{14}$.

\section{El surgimiento de la gobernanza}

Los expertos en el tema (entre los que hay que incluir a Joan Prats que ya en el año 1984 tradujo un libro de Crozier, significativamente titulado "No se cambia la sociedad por decreto" para una colección del Instituto Nacional de Administración Pública ${ }^{15}$ ), consideran que la aparición de la gobernanza es consecuencia de los problemas que deja sin resolver el New Public Management.

Los dos problemas principales eran que la coordinación se había vuelto difícil, debido a la compartimentación de la gestión administrativa a que condujo la definición de funciones por fijación de objetivos concretos (de ahí lo de la coordinación descentralizada) y el que nos interesa más ahora: la imposibilidad de separar la concepción de las políticas de su ejecución ${ }^{16}$. Es decir que después de implantar una nueva manera de gestión en el seno de la administración pública, era necesario modificar también la manera como se decidían las políticas y los objetivos que la administración debía alcanzar.

En la práctica, este planteamiento traslucía una gran desconfianza respecto de la autonomía que pudieran tener los representantes políticos y perseguía su postergación. Para ello, lo que se hace es instaurar una especie de mandato imperativo que vincula a los representantes políticos a las instrucciones de los grupos sociales dominantes. Este mandato imperativo se vehicula por medio del establecimiento de canales de participación de los grupos de interés en la elaboración de las normas generales y en el diseño e implementación de las políticas públicas.

\section{MANIFESTACIONES DE LA GOBERNANZA}

\section{a) Las autoridades y/o agencias independientes en la UE}

Desde mi punto de vista, el fenómeno de las agencias y autoridades independientes (como la Agencia 
Europea del Medicamento o la Comisión del Mercado de las Telecomunicaciones) forma parte de la gobernanza en sentido estricto. No obstante, hay autores que las consideran como una forma de autorregulación ${ }^{17}$. En cualquier caso estos entes formarían parte de la constelación de la gobernanza.

En los países europeos, las agencias y autoridades independientes se generalizan cuando de produce la liberalización de los sectores monopolizados por el Estado (como las telecomunicaciones, la generación y distribución de energía, o la televisión). Para justificar su existencia se argumentó que en estos ámbitos existía la necesidad de unos cuerpos reguladores independientes del Estado. Ello era necesario para que no se vieran favorecidas las empresas estatales, antes monopolísticas, que ahora tenían que competir. Se señaló también que se trataba de ámbitos en los que era necesario un alto grado de conocimiento experto para poder regular dado su elevado índice de sofisticación tecnológica o de complejidad.

En realidad, por lo que respecta a las agencias independientes que se han creado a nivel europeo, el resultado de su implantación ha sido la privatización del proceso de toma de decisiones. Esta es al menos la conclusión general que extrae una estudiosa del tema, Michelle Egan, que señala que el resultado de la delegación reguladora a las diferentes agencias independientes europeas ha sido convertir a las empresas "en los actores dominantes en el proceso de policy making" ${ }^{18}$. No es extraño por ello, que en el contexto del debate sobre la llamada "constitución europea" las organizaciones empresariales y patronales abogasen por un mayor recurso a ese tipo de instancias en detrimento de los órganos legislativos “ordinarios” de la UE (que por otro lado están ya intensamente colonizados por los lobbies).

La privatización del proceso de toma de decisiones de las agencias "independientes" se produce por diversas vías. Una, la más obvia, es que en ellas se encuentren formalmente representados los grupos de interés económico. Es el caso, por ejemplo, de la ETSI (European Telecommunications Standards Institute, o Instituto Europeo de Normas de Telecomunicaciones). Se trata de la organización europea de estandarización de las telecomunicaciones y en sus órganos está representada la industria de las telecomunicaciones.

En otros casos, los mecanismos de privatización son más sutiles. Es lo que ocurre con la EMEA, la Agencia Europea del Medicamento. Esta entidad, creada en 1995, tiene como misión publicar directrices para controlar los requisitos de comprobación de la calidad, la seguridad y la eficacia de los medicamentos. También supervisa los medicamentos de uso humano y veterinario con carácter previo a la autorización para su comercialización. Se trata de algo similar a la Food and Drug Administration norteamericana (FDA) en versión europea.

En este caso, un experto en el tema señala que a industria farmacéutica ha sido la principal beneficiaria de la creación de la Agencia ${ }^{19}$. Esto se pone de manifiesto en el hecho de que su actuación ha sido mucho más favorable a los intereses de la industria que a los de la salud de los ciudadanos, en comparación con la actuación de las autoridades nacionales.

La capacidad que tiene la industria farmacéutica de condicionar las decisiones de la EMEA es el resultado de diversos factores. Uno es el hecho de que la agencia se financia fundamentalmente con tasas que paga la industria. Otro, son las formas que tiene la industria de influir en la designación de los "expertos" que van a elaborar los dictámenes. Y una tercera es la influencia que ejerce a través de las asociaciones de pacientes, que tienen representación en la EMEA, y que están financiadas por el lobby farmacéutico ${ }^{20}$. En esas circunstancias no es extraño que un dirigente de la Federación Europea de Industrias Farmacéuticas (EFPIA) haya llegado a afirmar que la EMEA, más que un regulador, es un "socio" de la industria ${ }^{21}$. 


\section{b) El “derecho negociado" en las agencias independientes norteamericanas.}

La figura de las agencias independientes es un fenómeno de mucha mayor antigüedad en Estados Unidos que en Europa. Su origen se remonta a 1887, cuando se creó la Comisión de Comercio Interestatal (ICC). Otras agencias son la entidad que se ocupa de la protección ambiental (The United States Environmental Protection Agency: EPA) o la Securities and Exchange Commission (SEC), que ha adquirido notoriedad como consecuencia de la última crisis financiera.

En los años noventa se establece un proceso normativo para estas agencias que constituye una de las manifestaciones de referencia de la gobernanza en sentido estricto. Se trata de The Negotiated Rulemaking Act de 1990, modificada en 1996. Esta ley establece un procedimiento participativo para los grupos de interés en la elaboración de la normativa administrativa.

Resulta significativa la enumeración de motivos que hace el Congreso para justificar la conveniencia de aprobar esta ley. Así, se dice que el procedimiento negociado puede hacer que las normas sean cumplidas con mejor voluntad, ya que se ha participado en su elaboración. Se señala también que es un mecanismo que transmite una mejor información sobre las preferencias de los ciudadanos o que las asociaciones de intereses son más próximas a sus miembros y más flexibles que las instancias estatales.

El procedimiento que establece la Negotiated Rulemaking Act consiste básicamente en lo siguiente: cuando se hace pública la decisión de iniciar un proceso de reglamentación negociado, hay que explicitar el objeto de la regulación y los intereses potencialmente afectados. La agencia que pretende elaborar la regulación debe proponer una lista de personas que representen los intereses afectados y un facilitador que represente a la agencia. Si alguien se considera injustamente excluido de esta lista puede recurrir.

Los representantes de intereses y el facilitador se reúnen en una comisión que tiene como objetivo alcanzar un consenso sobre el contenido de la reglamentación en cuestión. Si se llega a este consenso, la comisión elabora un proyecto y la agencia lo aprueba formalmente. La diferencia fundamental que existe entre este procedimiento y los existentes anteriormente es que en los anteriores las consultas a los stakeholders (afectados) se hacían de forma separada e informal. Es decir, no se les ponía a negociar conjuntamente de forma pública.

Los estudios empíricos que se han realizado sobre el resultado del procedimiento de regulación negociada ponen de manifiesto que éste hace más sensible a la

administración respecto a los intereses de aquéllos a quienes afecta. Sin embargo, esta sensibilidad se distribuye de forma desigual: "detecta" mejor los intereses de quienes tienen más recursos (por ejemplo, los de las grandes empresas respecto a las pequeñas $)^{22}$.

En cualquier caso, los autores que defienden la "racionalidad" de este tipo de procedimientos no son capaces de poner de manifiesto cómo se puede conseguir que las partes no se dediquen única y exclusivamente a defender sus intereses particulares.

Así, en un artículo del profesor William H. Simon ${ }^{23}$, este autor sostiene que en el transcurso de la negociación se produce una pérdida de perspectiva de los propios intereses. Cuando los participantes en la negociación empiezan a buscar soluciones mutuamente beneficiosas, su concepción del problema cambia. Pierden la perspectiva que les permite saber qué es lo que les beneficia y qué es lo que les perjudica. Sería una situación similar a la "posición original" de Rawls. Sin embargo, el 
profesor Simon no es capaz de explicar convincente cómo se produce ese bootstrapping, como él lo denomina: ese fenómeno consistente en ir más allá de los propios intereses sin contar con nada más que esos intereses propios.

c) La participación de la sociedad civil en los procesos de toma de decisiones de la UE: Nothing but consultation.

La participación de la sociedad civil es un componente central de la retórica de la gobernanza. Constituye un elemento de legitimación aducido por las instituciones europeas, especialmente la Comisión, para fundamentar sus actuaciones. La participación de la sociedad civil es presentada como una forma de salvar el vacío que separa a la UE y a sus ciudadanos. Se trata de un elemento de la gobernanza europea que pretende superar el llamado "déficit democrático" que padecen las instituciones europeas. Y, de hecho, el Tratado de Lisboa obliga a las instituciones de la UE a "mantener un diálogo abierto, transparente y regular con las asociaciones representativas y con la sociedad civil” (art. 8B).

Ahora bien, más allá de estas declaraciones retóricas, ¿cuál es la realidad de la participación de las organizaciones de la sociedad civil en los procesos de toma de decisiones de la UE? Con esta pregunta nos referimos a organizaciones no estatales, ni empresariales, y que no buscan defender los intereses de sus miembros. Se hace referencia a las ONG's o movimientos sociales que actúan en aras del bien común y de valores ampliamente compartidos. ¿Qué papel tiene este sector de la sociedad civil en la UE? (pues que las organizaciones de intereses, especialmente empresariales, realizan un intenso papel de lobby sobre las instituciones europeas es algo que sabemos ya hace tiempo).

A responder esta pregunta va dirigido un trabajo publicado en 2008 por Sandra Kröger, discípula de una de las mayores expertas en el tema de la gobernanza europea (Kohler-Koch). El título del artículo ya pone de manifiesto que las conclusiones no son demasiado halaguieñas: "Nothing but consultation", es decir que parece que lo que hacen las instituciones europeas es limitarse a "consultar" a estas asociaciones ${ }^{24}$.

Más concretamente, el método del trabajo aplicado en esta investigación consistió en analizar los números de 26 revistas académicas relevantes correspondientes a los últimos diez años. Se seleccionaron aquellos artículos que trataban del tema de la participación de las organizaciones de la sociedad civil en los procesos de policy making europeos, en particular en los campos de asuntos sociales, salud, protección del consumidor, medio ambiente y comercio.

La pregunta central que se pretendía contestar es: “¿Qué podemos decir acerca del lugar y del papel de las organizaciones de la sociedad civil tras el examen de la literatura relevante?" Y las conclusiones, como ya se ha apuntado, resultaron bastante decepcionantes (disillusioning).

Para analizar el material, la autora, se planteo fundamentalmente dos cuestiones. La primera hacía referencia al grado de acceso que tenían las organizaciones de la sociedad civil para poder expresar sus puntos de vista ante los órganos decisorios de la UE. La segunda cuestión tenía que ver con el grado en que las opiniones expresadas eran efectivamente tenidas en cuenta.

En cuanto a la primera de las cuestiones, la relativa a la capacidad de acceso a las instituciones comunitarias, se constata que existe una enorme variedad de mecanismos para que las organizaciones de la sociedad civil expresen sus puntos de vista. Desde encuentros informales entre funcionarios de la Comisión y representantes de la sociedad civil hasta seminarios formalmente institucionalizados 
sobre la base de disposiciones comunitarias específicas. En cualquier caso, formales o no, estos encuentros se realizan siempre de modo casi exclusivo en la fase preparatoria del proceso de policy making y no en las etapas resolutivas.

Por lo que respecta a la pretensión de que los puntos de vista de los representantes de la sociedad civil sean tenidos en cuenta, el modo como Sandra Kröger entiende que se cumpliría esa exigencia es el siguiente: que los actores puedan debatir frente a frente, interactuar comunicativamente, intercambiar ideas con los demás interlocutores y, eventualmente llegar a un consenso o a un acuerdo que sea capaz de representar todos los puntos de vista presentes.

Sin embargo, ya el libro blanco del 2001 puso de manifiesto que no se pretendía poner en marcha ni siquiera un procedimiento de regulación negociada al estilo americano. En aquel documento se señalaba que las consultas "permiten a la Comisión y a las restantes Instituciones arbitrar entre las pretensiones y prioridades en conflicto y definir las políticas". No hay, por tanto, debate, sino que son la Comisión y el resto de instituciones las que determinan qué es lo que va a ser tomado en consideración y en qué medida.

La conclusion de Sandra Kröger no difiere de la que se podía extraer del documento del 2001. La autora considera que en realidad no se desea que se produzca una deliberación. Las invitaciones para participar en los encuentros se mandan con muy poca antelación, los encuentros no permiten que haya espacio para la comunicación horizontal entre los participantes y las consultas on line suelen tener predefinidas las respuestas.

En realidad, se trata de unos procedimientos que obedecen más a la lógica de la gobernabilidad que a la de la profundización de la democracia. Lo que le interesa a la Comisión es obtener elementos para mejorar sus propuestas y asegurarse un consenso preventivo. Pues quienes participan en las consultas adquieren implícitamente el compromiso de respetar dichas prácticas de consulta y de respetar también las decisiones de la Comisión.

En un marco de participación así concebido, no es de extrañar que los planteamientos más críticos resulten excluidos de los procesos de consulta, dejando de ese modo el campo expedito a las posturas más cercanas a los planteamientos oficiales de corte fundamentalmente neoliberal.

\section{CONCLUSIÓN}

Como ha señalado José Luis Gordillo en numerosas discusiones, "gobernanza" viene de "gobernabildad". Su genealogía debe buscarse en el informe de la Comisión Trilateral de 1975 sobre la crisis de las democracias ${ }^{25}$. En este informe se señalaba que los ciudadanos y grupos de las sociedades democráticas estaban exigiendo un volumen excesivo de derechos y reivindicaciones, que sobrecargaban la capacidad de respuesta del Estado. Uno de los autores del informe, Huntington, llegaba a afirmar que una de las causas de la crisis de las democracias era el exceso de participación.

La estrategia que el informe planteaba para hacer frente a la crisis de gobernabilidad de las democracias consistía en la contención de las reivindicaciones de la sociedad respecto del Estado. Era preciso que los ciudadanos no plantearan tantas exigencias. Las recetas para conseguir estos objetivos fueron, como es sobradamente sabido, la desregulación, la expansión del mercado, las privatizaciones y las liberalizaciones, que contribuyeron a disciplinar a la población, inculcaron planteamientos individualistas como filosofía de vida y redujeron los recursos asistenciales estatales. 
Como señala Boaventura de Sousa Santos, la gobernanza surge cuando se hacen evidentes los límites del mercado como mecanismo de regulación social ${ }^{26}$.

Es la necesidad de un nuevo tipo de mecanismo de toma de decisiones y de gestión de la administración lo que da lugar al surgimiento de lo que aquí se ha llamado la "constelación de la gobernanza".

Con esos antecedentes, es obvio que la gobernanza no puede ser un instrumento de cambio social, ni siquiera en el caso de autores progresistas bienintencionados como Roberto Mangabeira Unger. Lo que importa en última instancia en el caso de la gobernanza es el mantenimiento del orden capitalista y no el fomento de la participación democrática. La gobernanza no trata de participación popular, ni de transformaciones sociales, sino de solución de problemas y de negociación entre sectores interesados. No cuestiona la correlación de fuerzas existente ni se plantea objetivos redistributivos. Y el estado es el metarregulador, quien crea el espacio para la negociación entre los grupos de intereses. Por ello, se contrapone a la participación autodeterminada, es decir, al movimiento popular que surge desde la sociedad y elabora él mismo sus reivindicaciones.

Boaventura de Sousa Santos contrapone a la gobernanza la que llama "globalización contrahegemónica" 27 . Esta es llevada a cabo por las organizaciones y movimientos sociales que luchan contra la globalización neoliberal. El Foro Social Mundial sería una de sus manifestaciones. Ahí sí se cree que otro mundo es posible y se intenta honestamente profundizar la democracia.

Pero como señala también Sousa Santos, la globalización contrahegemónica y la gobernanza tienen lenguajes parecidos y utilizan expresiones similares. Las dos hablan de "horizontalidad", “autorregulación”, “voluntariedad", "asociación en red"...Por eso, resulta importante no dejarse confundir. Para ello es necesario distinguir siempre la dimensión retórica y la dimensión efectiva de las propuestas que se realizan y los procedimientos que se ponen en práctica. Que los mecanismos reales tal como funcionan en la práctica respondan a una lógica de la gobernabilidad (de cómo asegurar que se van a poder tomar decisiones e imponerlas) o a la de la profundización de la democracia, es una de las piedras de toque fundamentales para distinguir la lucha contra la barbarie de lo que son contribuciones a su perpetuación.

\section{NOTAS}

${ }^{1}$ V. GALGANO, F.: "Lex mercatoria, shopping del derecho y regulaciones contractuales en la época de los mercados globales", Revista De Derecho Mercantil , 2003, N 247 pp. 7-20.

${ }^{2}$ V. Yves Dezalay: Multinationales de l'expertise et "dépérissement de l'État" Actes de la Recherche en Sciences Sociales, 1993, 96, 1 pp. 3 - 20.

${ }^{3}$ Jurgen Habermas "Law as Medium and Law as Institution" en Gunther Teubner(ed.): Dilemmas of Law in the Welfare State, Berlin, Walter de Gruyter, 1988 p. 203-220.

${ }^{4}$ Gunther Teubner(ed.): Dilemmas of Law in the Welfare State, Berlin, Walter de Gruyter, 1988

${ }^{5}$ V. p. ej. el libro de Esteve Pardo sobre este tema: Autorregulación: génesis y efectos, Editorial Aranzadi, 2002.

${ }^{6}$ V. los trabajos sobre este tema incluidos en Sousa Santos, B. d. y Rodriguez Garavito, C. A. (eds.): $E l$ derecho y la globalización desde abajo, Barcelona, Anthropos, 2007. 
${ }^{7}$ V. CROZIER, M.: No se cambia la sociedad por decreto, Madrid, Instituto Nacional de Administración Pública, 1984, p.192.

${ }^{8}$ V. Aberbach, J. D. \& Christensen, T.: "Translating Theoretical Ideas into Modern State Reform EconomicsInspired Reforms and Competing Models of Governance" en Administration \& Society, 35, 2003, pp. 491509.

${ }^{9}$ V. Sabel, C. F. « Révolution tranquille de la gouvernance démocratique: vers une démocratie expérimentale », en OCDE : La gouvernance au XXIe. Siècle, 2001, pp. 141-176.

${ }^{10}$ Power, M.: The Audit Explosion, London, Demos, 1995.

${ }^{11}$ V. Michael Power: "Evaluating the Audit Explosion”, en Law \& Policy, 25, 3, 2003, pp.185-202.

${ }^{12}$ V. respecto al caso y sus consecuencias el editorial de la revista Nature $\mathrm{n}^{\circ} 444$, dic. 2006, pp. 971-972.

${ }^{13}$ William H. Simon: "Solving Problems V. Claiming Rights: The Pragmatist Challenge to Legal Liberalism", Public Law \& Legal Theory Working Paper Group, Columbia Law School, version de 1 de agosto de 2003.

${ }^{14}$ UNGER, R. M.: Democracia realizada. A alternativa progressista, Sao Paulo, Bontempo editorial, 1999.

${ }^{15} \mathrm{~V}$. nota 7.

${ }^{16}$ V. Joan Prats: De la burocracia al management: del management a la gobernanza. Las transformaciones de las administraciones públicas de nuestro tiempo, Madrid, Instituto Nacional De Administración Pública, 2005.

${ }^{17}$ Es el caso de Esteve Pardo en el libro citado más arriba.

${ }^{18}$ Michelle Egan: "Regulatory Strategies, Delegation and European Market Integration, en Journal of European Public Policy, 5, 3, septiembre de 1998.

${ }^{19}$ Govin Permanand: EU Pharmaceutical Regulation: The Politics of Policy-Making, Manchester University Press, 2006, p. 118.

${ }^{20}$ V. a este respecto la denuncia de Health Action International Europe en el documento titulado: "Does the European Patients' Forum represent patient or industry interests?" de 14 de Julio de 2005, que puede encontrarse en Internet.

${ }^{21}$ Govin Permanand, op. cit. p.137.

${ }^{22}$ Laura I. Langbein: "Responsive Bureaus, Equity, and Regulatory Negotiation: An Empirical View", en Journal of Policy Analysis and Management, Vol. 21, No. 3, 2002, pp. 449-465.

${ }^{23}$ V. nota 13.

${ }^{24}$ Kröger, Sandra: "Nothing but consultation: The place of organised civil society in EU policy-making across policies", European Governance Papers (EUROGOV), № C-08-03 2008 http://www.connexnetwork.org/eurogov/pdf/egp-connex-C-08-03.pdf.

${ }^{25}$ Michel Crozier, Samuel P. Huntington y Joji Watanuki: The Crisis of democracy. Report on the governability of democracies to the Trilateral Commision, New York University Press, 1975. 
Las Nuevas Formas de Regulación Neoliberal

${ }^{26}$ Sousa Santos, B. de: "Más allá de la gobernanza neoliberal: el Foro Social Mundial como legalidad y política cosmopolitas subalternas", en Sousa Santos, B. d. y Rodriguez Garavito, C. A. (eds.): El derecho y la globalización desde abajo, Barcelona, Anthropos, 2007, pp. 31-60.

${ }^{27}$ Ibidem. 